\title{
AVALIAÇÃO ENQUANTO INSTRUMENTO PARA NORTEAR A INCLUSÃO ESCOLAR
}

\author{
EVALUATION AS NA INSTRUMENTO TO GUIDE SCHOOL INCLUSION
}

\author{
Stephânia Cottorello VITORINO ${ }^{1}$ \\ Sonia Maria Duarte GREGO²
}

\begin{abstract}
RESUMO: O presente trabalho é um recorte da Tese de Doutorado etem como objetivodiscutir a avaliação escolar dentro do contexto inclusivo, em uma escola para todos. Primeiramente é abordado o impasse da avaliação e os conflitos que a mesma proporciona para alunos, professores e gestores. Também é abordado o papel da avaliação classificatória, construída culturalmente, portanto, distante do seu objetivo enquanto instrumento de reflexão sobre a ação pedagógica e consequentemente sobre a aprendizagem do aluno. Em seguida, é abordada a educação para todos, mais especificamente o aluno com deficiência intelectual no contexto de uma escola inclusiva, e a avaliação enquanto instrumento capaz de nortear uma educação que realmente atenda as necessidades específicas de cada aluno.
\end{abstract}

PALAVRAS-CHAVE: Educação inclusiva. Avaliação. Deficiência intelectual.

ABSTRACT: The present work, is a part from the PhD thesis and aims to discuss school evaluation within the inclusive context, in a school for all. Firstly, the impasse of assessment and the conflicts it provides for students, teachers and managers are addressed. It also addresses the role of classificatory assessment, culturally constructed, therefore, far from its objective as an instrument for reflection on pedagogical action and consequently on student learning. Next, education for all is addressed, specifically the student with intellectual disability in the context of an inclusive school, and evaluation as an instrument capable of guiding an education that truly meets the specific needs of each student.

KEYWORDS: Inclusive education. Assessment. Intellectual disability.

A avaliação escolar tem sido tema de grandes discussões no ambiente escolar e tem proporcionado momentos de conflitos entre professores, alunos e gestores. Tem envolvido grandes estudiosos e pesquisadores que buscam alicerçar caminhos que deem parâmetros para que o professor possa construir uma nova concepção de avaliação e que muitas vezes implica a ruptura de conceitos tradicionalmente construídos. O desconstruir a prática alicerçada culturalmente em avaliação como classificação, requer mudança e nova postura diante da

${ }^{1}$ Universidade Estadual Paulista (Unesp), Faculdade de Ciências e Letras, Araraquara - SP - Brasil. Doutora pelo Programa de Pós-Graduação em Educação Escolar. E-mail: stephaniacv@ yahoo.com.br.

${ }^{2}$ Universidade Estadual Paulista (Unesp), Faculdade de Ciências e Letras, Araraquara - SP - Brasil. Professora Adjunto do Departamento de Didática. E-mail: sonya.grego@gmail.com.

Doxa: Rev. Bras. Psicol. Educ., Araraquara, v.19, n.2, p. 200-211, jul./dez. 2017. 
democratização do ensino de uma escola para todos. De acordo com Perrenoud (1999), a avaliação nasceu com os colégios por volta do século XVII e tornou-se indissociável do ensino de massa que conhecemos desde o século XIX, com a escolaridade obrigatória.

Deparamo-nos, dessa forma, com um sistema antigo de avaliação, cujo objetivo era classificar, criar hierarquias, certificar e rotular, menos o caráter de diagnóstico sobre o objeto avaliado, que segundo Luckesi (1995, p. 43):

Para não ser autoritária e conservadora, a avaliação terá de ser diagnóstica, ou seja, deverá ser o instrumento dialético do avanço, terá de ser o instrumento da identificação de novos rumos. Enfim, terá de ser o instrumento do reconhecimento dos caminhos e da identificação dos caminhos a serem perseguidos.

Tomamos consciência de que a avaliação que realizávamos estava deixando de fazer seu verdadeiro papel, que seria refletir sobre a prática pedagógica, em busca de servir a um modelo de conservação e reprodução de uma sociedade ainda autoritária.

A avaliação passa a ter também um papel disciplinador, pois o professor detém o poder de aplicar a avaliação com ameaças de notas, de humilhação e de reprovação. E é essa desconstrução que será necessário acontecer, para que a avaliação seja vista como um instrumento capaz de nortear a aprendizagem do aluno e a prática do professor.

Para Hadji (1994) a avaliação é um meio de comunicação social e deve fornecer ao aluno informações que ele possa compreender e que lhe sejam úteis.

Tal instrumento precisa permitir a aproximação entre ensino e aprendizagem, ou seja, entre o professor e aluno, não o distanciamento entre ambos, devido ao desconforto que ela poderá causar se não for vista como um instrumento indispensável e favorável ao processo educacional.

Diante disto, observamos assim, a necessidade da avaliação ser formativa e transformada para atender às reais necessidades da aprendizagem do aluno, como afirma Perrenoud, “[...] é formativa toda avaliação que ajuda o aluno a aprender a se desenvolver, ou melhor, que participa da regulação das aprendizagens e do desenvolvimento no sentido um projeto educativo.” (PERRENOUD, 1999, p.103).

A avaliação, nesse contexto, permite o acompanhamento e a reflexão sobre o desenvolvimento do aluno, tornando-se indissociável à construção do saber.

Outro tema que ainda proporciona grandes discussões no interior da escola, trazendo inquietações e insegurança é a escola para todos, mais especificamente a inclusão escolar de alunos público alvo da educação especial. Acreditamos que será necessário romper com a 
escola seletiva que está arraigada culturalmente e historicamente no interior da escola, porém o desafio maior além da desconstrução é a construção de uma nova cultura escolar para uma escola que contemple a todos.

A educação inclusiva contempla o desenvolvimento do aluno na sua totalidade, na aprendizagem do conteúdo, na aprendizagem social e na aprendizagem afetiva.

O aluno com deficiência intelectual (DI), apresenta desenvolvimento de aprendizagens diferentes dos demais alunos, necessitando que o professor amplie o olhar para as diferenças e adeque seu trabalho à necessidade do aluno, sendo que sua

[...] capacidade de abstração e generalização também se mostra mais limitada, e eles podem, ainda, ter maior dificuldade para formação de conceitos e memorização. Geralmente demonstram dificuldade quando lhes são comunicadas duas ou mais ordens complexas, ou quando são obrigados a processar rapidamente uma grande gama de informação e/ou estimulação. Podem também experimentar problemas para se adaptar a novas situações, bem como para expressar e/ou controlar suas emoções. Atrasos no desenvolvimento psicomotor, da percepção sensorial, linguagem e comunicação são muito comuns. Quase sempre esses sujeitos apresentam uma significativa imaturidade social comparada com pessoas da mesma idade. (GLAT et al., 2009, p. 81).

O aluno com deficiência intelectual apresenta um desenvolvimento diferenciado a nível cognitivo na sua maneira de aprender, dentro de um tempo diferente dos demais pares de sua idade, necessitando de recursos diferenciados e com intervenções planejadas e constantes, para que aconteça inclusive uma resposta, diante do que lhe é apresentado.

Diante das questões da avaliação e da educação inclusiva, como sendo dois temas que ainda geram conflitos na escola advindos da insegurança do professor, e de uma estrutura educacional que grita por uma reorganização em seu sistema político, ético e profissional.

Falar de uma educação com qualidade para todos, é falar de uma escola que não é engessada pelas circunstâncias momentâneas de seu dia a dia, mas sim de uma escola que se autoavalie continuamente para que o processo da melhoria seja constante em busca de mudanças concretas para acompanhar o processo de ensino e aprendizagem de todos os seus alunos. Uma escola inclusiva está alicerçada na democracia e na constante mudança e desenvolvimento que ocorrem na sociedade como um todo e não somente na especificidade de um grupo de alunos.

Uma escola inclusiva é envolvida com questões de valores que estão presentes e que devem ser trabalhados no conjunto das atribuições que fazem parte da escola, com todos os que compõem a escola, tais como a igualdade, respeito às diversidades, direitos, participação, 
confiança, esperança, coragem, ética, canalizando todos esses valores de forma a proporcionar momentos constantes e diários como forma a envolver também a comunidade escolar e assim influenciar com ações uma sociedade em constante evolução.

Segundo a Declaração de Salamanca (UNESCO, 1994, alínea 1) “[...] toda criança possui características, interesses, habilidades e necessidades de aprendizagem que são únicas.”, e esta afirmação não está sendo reportada a criança com algum tipo de deficiência e sim a todas as crianças, ou seja, todas as crianças tem sua maneira de abstrair e de aprender, porém essa mesma Declaração enfatiza que “[...] os sistemas educacionais deveriam ser designados e programas educacionais deveriam ser implementados no sentido de se levar em conta a vasta diversidade de tais características e necessidades.” (UNESCO, 1994, alínea 1).

A educação inclusiva é um campo que se encontra marcado por imperativos que devem ser analisados sob várias perspectivas, pois sua proposta inovadora pressupõe um remanejamento e uma reestruturação radicais na dinâmica da escola. (SAMPAIO; SAMPAIO, 2009, p. 57)

A escola inclusiva faz das diversidades existentes, pontos favoráveis para a participação de todos no processo educacional, com ações que remetem ao desenvolvimento singular de todos.

Ao tratar de cunho pedagógico centrado nas necessidades de aprendizagem para todos, o referido parecer afirma:

Em vez de focalizar a deficiência da pessoa, [o termo] enfatiza o ensino e a escola, bem como as formas e condições de aprendizagem; em vez de procurar, no aluno, a origem de um problema, define-se pelo tipo de resposta educativa e de recursos e apoios que a escola deve proporcionar-lhe para que obtenha sucesso escolar; por fim, em vez de pressupor que o aluno deve ajustar-se a padrões de "normalidade" para aprender, aponta para a escola o desafio de ajustar-se para atender a diversidade de seus alunos. (CONSELHO NACIONAL DE EDUCAÇÃO, 2001, p. 14).

A escola precisa tornar-se um local de aprendizagem para todos, e é com essa dinâmica de refletir sobre o que está sendo oferecido (recursos, metodologias, planejamento, adaptação, avaliação etc.), que se tem atingido de maneira significativa as necessidades reais dos alunos.

Para a escola tornar-se um local de aprendizagem, será necessário envolver a todos que compõem a escola (gestão, coordenação, equipe da secretaria, da organização da escola, etc.) e não somente o professor, a escola inclusiva requer uma reorganização da concepção da atual escola. 
Para tanto, há necessidade de analisar como estão sendo dirigidos não só a aprendizagem dos alunos, mas como está sendo avaliado o processo de ensino-aprendizagem dos alunos na escola inclusiva. Reportamo-nos aos estudos de NeusAgut do Instituto CanPeixauet Barcelona que traz os seguintes pontos sobre a avaliação na escola inclusiva:

As significativas aprendizagens em contextos inclusivos será acompanhada por um tipo de avaliação que deve ser caracterizada como sendo: funcional, significativa e abrangente e generalizáveis. Funcional e global, porque temos de dar informações sobre o processo seguido pelo aluno para ajustar o ajuda a aprender e melhorara práticas de ensino. Significante e generalizáveis, porque entre as atividades e os processos de ensino e aprendizagem do aluno de forma contextual e, por sua vez, transversal. (HORNA, 2010, p. 43, tradução nossa).

O objetivo da educação é promover o desenvolvimento dos alunos e para saber se este desenvolvimento está acontecendo, há necessidade de avaliar o processo no qual o aluno está contextualizado, com atividades, metodologias pensadas e planejadas para sanar as dificuldades de todos os alunos.

Nos dizeres de Luckesi, (2011, p. 68),

O planejamento define os resultados e os meios a serem atingidos; a execução constrói os resultados; e a avaliação serve de instrumento de verificação dos resultados planejados que estão sendo obtidos, assim como para fundamentar decisões que devem ser tomadas para que os resultados sejam construídos.

Quando estendemos a discussão sobre avaliação, perpassamos o nosso olhar também para o desempenho do trabalho do professor, pois se o objetivo da avaliação é saber sobre o desenvolvimento do aluno nos conteúdos escolares, diretamente estamos focando o nosso olhar também às condições para que este desenvolvimento aconteça no seu curso normal. Sobre a avaliação do trabalho da professora, Weisz e Sanches (2006, p. 95) sinalizam que:

Avaliar a aprendizagem do aluno é também avaliar a intervenção do professor, já que o ensino deve ser planejado e replanejado em função das aprendizagens conquistadas ou não.

As autoras também enfatizam que:

Ao montar uma situação de avaliação, o professor precisa ter clareza sobre as diferenças que existem entre situações de aprendizagem e situações de avaliação. (WEISZ; SANCHES, 2006, p.95). 
E é no papel de observador que o professor, através de suas avaliações contínuas, poderá obter indicadores que nortearão a sua prática na intervenção de um trabalho focado no desenvolvimento de seus alunos, em que poderá planejar e replanejar o ensino, buscando sim o sucesso de seu trabalho, porém e exatamente respeitando a diversidade individual de todos os alunos, tendo, de forma nítida, que as formas de aprender, o tempo, e a construção do conhecimento são particularidades e subjetividades, que precisam sim ser observadas, respeitadas e trabalhadas para que o aluno tenha condições favoráveis para seu desenvolvimento e não condições contrárias. Nas palavras de Hoffmann (2006, p. 73),

Avaliar é essencialmente questionar. É observar e promover experiências educativas que signifiquem provocações intelectuais significativas no sentido do desenvolvimento do aluno.

A prática avaliadora sobre a ação do professor em sala de aula oferece informações de grande valia para análise dos processos de aprendizagem e sua efetivação. Tal prática precisa acontecer como uma forma de auto-avaliação que trará uma reflexão sobre a ação da prática, em que esta se estende a metodologias, conteúdos, currículos, estratégias, objetivos e recursos. Refletir sobre a prática permite ter um olhar mais detalhado em que identificará possibilidades e dificuldades encontradas no processo da aula e, consequentemente, da aprendizagem de conteúdos pelos alunos. E fazendo essa avaliação sobre a prática do professor, sobre a participação do aluno e sobre as ações da escola, há possibilidade de reflexão de medidas que precisam ser tomadas para ajustes necessários ao planejamento de uma escola inclusiva, de uma escola que não está somente aberta para todos e sim tem condições de articular ações para que todos sejam recebidos e desenvolvidos em suas reais potencialidades, com as devidas possibilidades planejadas pela escola e consequentemente pelo professor. Sendo assim, avaliar para promover significa compreender a avaliação como um instrumento capaz de melhorar a ação pedagógica, em seu contexto, ação mediadora, capaz de promover ações e recriar alternativas que vão ao encontro de benefícios dos alunos. (HOFFMANN, 2006).

A avaliação pode tornar-se mediadora de uma nova proposta educacional, independentemente dos instrumentos utilizados, proporcionando além de achados sobre o desenvolvimento do aluno, o diálogo entre professor-aluno-pais-escola, sendo portando uma avaliação mediadora, da qual os alunos também participam da construção de seu conhecimento, observando, dialogando, mostrando suas dificuldades, suas habilidades de forma natural, e não se sentindo culpado e excluído por suas particularidades. 
Um dos entraves da educação inclusiva é avaliação, e Valentim (2011, p. 113) em seus estudos comprovou que:

[...] a avaliação da aprendizagem do aluno com DI, que tem-se mostrado, entre tantos outros, um nó na educação, precisa ser desatado para que a inclusão escolar se transforme em prática efetiva. A escola, enquanto espaço da diversidade, da heterogeneidade, deve ter como ação imediata a substituição de práticas avaliativas restritas e estáticas por práticas que respondam às especificidades do aluno com deficiência - algumas delas citadas em nosso trabalho - e, dessa forma, oferecer a esses alunos a oportunidade de máxima aprendizagem, de inserção na sociedade, em igualdade de condições educativas.

A avaliação é uma questão também estritamente polêmica em se tratando do aluno com deficiência intelectual na rede regular de ensino, no sentido em que é necessário pensar em adequar a avaliação de acordo com as características do aluno, no sentido que ela passe a ser significativa para ele e para o professor, com resultados que tragam direcionamento à reflexão sobre a prática desse professor.

Há necessidade de conscientizar os professores sobre as formas de avaliação, ou melhor, de conscientizar que o papel da avaliação não é estar a favor ou contra alguém e sim disponibilizar caminhos através da mediação capazes de nortear a ação do professor e do aluno rumo ao desenvolvimento.

Nas palavras de Ramírez (2010, p. 24, tradução nossa),

A avaliação inclusiva, conceituada como "avaliação tolerante" dentro do indicador de processo educacional é definida em relação a três subindicadores: a obtenção de informações através de várias fontes, a implementação efetiva da avaliação e utilização de técnicas de avaliação e auto avaliação pelos pares em curso.

Nas palavras de Hoffmann (1991, p. 67, grifo do autor),

O que pretendo introduzir neste texto é a perspectiva da ação avaliativa como uma das mediações pela qual se encorajaria areorganização do saber. Ação, movimento, provocação, na tentativa de reciprocidade intelectual entre os elementos da ação educativa. Professor e aluno buscando coordenarseus pontos de vista, trocando ideias, reorganizando-as.

Os autores C. Duk e F. J. Murillo (2012, p. 11), em seus estudos abordaram a avaliação como prestação de informação, mostrando algumas de suas características, 
A avaliação contínua, flexível e dinâmica, que acompanha todo o processo de educação aprendizagem e tem como objetivo principal a prestação de informação e, no início, durante e no final do processo de tomada de decisão. Isto é, a fim de mostrar o ponto de partida dos estudantes em relação à aprendizagem esperado, feedback e ajustar o processo da educação de acordo com as características e necessidades dos alunos, e verifique se eles têm alcançado ou não, e em que medida, a aprendizagem.

Mencionam a avaliação como uma característica muito relevante que é o feedback, recurso imediato capaz de situar o aluno nos caminhos que ele está percorrendo, ao elaborar uma hipótese ou a própria atividade escolar.

Feedback é uma palavra inglesa que significa realimentar ou dar resposta a uma determinado pedido ou acontecimento. Neste sentido, o feedback é um instrumento da avaliação formativa que pode ser usado e sem elaboração de recursos materiais, ou seja, é um componente da avaliação que é usada de forma oral e é capaz de fazer o aluno repensar sobre as estratégias que está utilizando para resolver determinadas atividades. Um procedimento capaz de atender e de avaliar o aluno em tempo real e de forma individualizada e melhor, com a participação do aluno.

O desafio maior dentro de uma escola com novas perspectivas de uma educação para todos, é entender que o aluno também pode fazer parte de forma significativa da construção do seu saber, com suas próprias habilidades e características, sem deixar de valorizar a ação do professor como profissional capaz de caminhar junto nesta construção. Para tanto, será necessário o professor perpassar também além de conhecimentos científicos necessários para sua boa atuação, passar também pela sensibilização.

De acordo com Fernandes (2009, p. 39),

A melhoria das aprendizagens dos alunos está fortemente associada à utilização sistemática de práticas de avaliação formativa, que tem vindo a ser recentemente designada como avaliação para as aprendizagens em contraste com a avaliação sumativa, designada como avaliação das aprendizagens. A avaliação para as aprendizagens é um processo eminentemente pedagógico, integrado no ensino e na aprendizagem, contínuo, interactivo e cujo principal propósito é o de melhorar o que, e como, os alunos aprendem.

E é nesse sentido que a escola precisa apropriar-se de tal instrumento, um instrumento capaz de instruir os passos do professor diante dos avanços de seus alunos ou não, ou seja, quando este mesmo instrumento aponta a dificuldade de desenvolvimento que o aluno está tendo em determinado momento ou no conteúdo trabalhado. A avaliação pode e deve proporcionar um diálogo entre professor e aluno e entre o professor e sua própria ação. É 
inaceitável que o mundo em plena mudança social, econômica, cultural e educacional ainda tenha uma avaliação defasada e descontextualizada da nova sociedade educacional, tendo como objetivo pontuar o que o aluno sabe e o que não sabe. Com a escola para todos, os processos, instrumentos e metodologias precisam acompanhar esses avanços para que a escola não fique tão distante de sua real função.

Instrumentos capazes de acompanhar o rendimento escolar do aluno são instrumentos que fornecerão respostas sobre o desenvolvimento, e que poderão se apresentar de diversas formas como relatórios descritivos de observações e portfólios de atividades. O importante na avaliação é a informação que ela irá proporcionar sobre o desempenho do aluno, e como ela irá transformar e formar a atuação do professor frente a essa resposta.

Observamos, assim, a necessidade da avaliação ser formativa e transformada para atender às reais necessidades da aprendizagem do aluno, como afirma Perrenoud, “[...] é formativa toda avaliação que ajuda o aluno a aprender a se desenvolver, ou melhor, que participa da regulação das aprendizagens e do desenvolvimento no sentido um projeto educativo.” (PERRENOUD, 1999, p. 103).

Neste contexto, não importa quais os instrumentos avaliativos que o educador irá utilizar para fazer uma avaliação formativa, e sim a forma com que irá extrair os resultados e adaptá-los a sua prática ao encontro das necessidades do aluno.

Em um estudo realizado por Santiueste e Arranz (2009), sobre a concepção da avaliação no processo de ensino-aprendizagem nos centros inclusivos de educação primária, na Agência Europeia, com a participação de 23 países, os autores nortearam os seguintes elementos, destacando que o propósito da educação deve ser a participação de todos os alunos estando a escola organizada:

- Todos os procedimentos de avaliação devem ser ligados ao currículo escolar e elaboração de relatórios sobre a aprendizagem, promovendo o uso de vários procedimentos.

- Promover a aprendizagem de todos os alunos considerando a avaliação como uma ferramenta de acompanhamento efetivo dos progressos e planejamento.

- A identificação e desenvolvimento de potencialidades e competências exige treinamento direito a ser coberto por programas de formação inicial e contínua de professores e especialistas.

- Impedir o propósito "formativo" da avaliação é prática distorcida ou perdida, o que ocorre quando se usa métodos de avaliação quantitativos, exclusivos.

- Comunicar aos alunos e famílias, os objetivos dos procedimentos de avaliação, como um processo positivo que salienta o progresso individual. 
- Evitar excessivamente procedimentos burocráticos de avaliação reforçando a autonomia da escola. A organização de um apoio eficaz é extremamente importante, com estruturas que permitam a colaboração e o trabalho em equipe entre os diferentes profissionais e serviços educação.

- A colaboração entre professores, planejamento e partilha de experiências da prática inclusiva.

- Envolvimento de alunos, pais e pares em atividades de avaliação contínua, planejada e apoiada na escola pela equipe de ensino e o tutor.

- Avaliação especializada na identificação inicial das necessidades educativas na avaliação no contexto de sala de aula.

- Variedade de recursos e instrumentos de avaliação, tais como manuais técnicos, materiais de avaliação em aspectos não acadêmicos, ferramentas de autoavaliação e de avaliação pelos pares, etc.

- Tempo dedicado a atividades relacionadas com a avaliação e garantir tarefas Cooperativas necessárias.

- Estar claramente ligada a outros aspectos como o financiamento e os recursos que suportam inclusão. (SANTIUSTE; ARRANZ, 2009, p. 472473, tradução nossa).

É com este olhar que retorno à discussão da escola para todos, após discutirmos a avaliação como mediadora desta nova escola e a postura do professor enquanto agente significativo desta transformação. Assume-se que a escola inclusiva é um processo de melhora e que na atuação dessa escola todos se beneficiam, seja nas atividades proporcionadas aos alunos, nas avaliações, nos recursos metodológicos, nos materiais, visto que tudo passa a ser pensado com muito cuidado, com especificidades, com sensibilidade, a desenvolver habilidades e sanar dificuldades e com isso todos ganham, os que apresentam algum tipo de deficiência ou não. Sendo, portanto, a avaliação o instrumento capaz de nortear ação do professor, enquanto mediadora do processo ensino aprendizagem, a partir do momento em que proporciona um olhar à individualidade e às necessidades de cada aluno, apontando as adequações que se faz necessárias para proporcionar um ensino que consiga atender a todos.

\section{REFERÊNCIAS}

CONSELHO NACIONAL DE EDUCAÇÃO. Institui as Diretrizes Nacionais para a Educação Especial na Educação Básica. Resolução n.2, de 11 de setembro de 2001. Diário Oficial da União: República Federativa do Brasil, Câmara de Educação Básica, Brasília, DF, 14 set. 2001. Disponível em: 〈http://portal.mec.gov.br/cne/arquivos/pdf/CEB0201.pdf>. Acesso em: 14 nov. 2017.

DUK, C.; MURILLO, F. J. Una evaluación inclusiva para una educación inclusiva. Revista Latinoamericana de Educación inclusiva, Chile, v.6, n.1, p.11-13, 2012. Disponível em: <http://www.rinace.net/rlei/numeros/vol6-num1/editorial.pdf>. Acesso em: 14 nov. 2017. 
FERNANDES, D. O papel dos professores no desenvolvimento da avaliação para as aprendizagens. In: CONGRESSO INTERNACIONAL DE EDUCAÇÃO, 8., 2009, Olinda. Anais... Olinda: Sapiens, 2009. Disponível em: <http://repositorio.ul.pt/bitstream/10451/5884/1/O\%20Pape1\%20dos\%20professores\%20no\% 20desenvolvimento\%20da\%20avaliac\%CC\%A7a\%CC\%83o.pdf>. Acesso em: 14 nov. 2017.

GLAT, R. et al. Estratégias pedagógicas para a inclusão de alunos com deficiência mental no ensino regular. In: GLAT, R. (Org.). Educação inclusiva: cultura e cotidiano escolar. Rio de Janeiro: 7Letras, 2009. p.81.

HADJI, C. A avaliação, regras do jogo: das intenções aos instrumentos. Porto: Ed. Porto, 1994.

HOFFMANN, J. M. L. Avaliar para promover: as setas do caminho. 9.ed. Porto Alegre: Mediação, 2006.

HOFFMANN, J. M. L. Avaliação: mito e desafio: uma perspectiva construtivista. Porto Alegre: Educação e Realidade, 1991.

HORNA, N. A. La evaluación em un modelo de escuela inclusiva. Aula de Innovación Educativa, Barcelona, n.191, p.42-44, mayo 2010. Disponível em:

<http://www.fapac.cat/sites/all/files/aula_2.pdf>. Acesso em: 14 nov. 2017.

LUCKESI, C. C. Avaliação da aprendizagem escolar: estudos e proposições. 22.ed. São Paulo: Cortez, 2011.

LUCKESI, C. C. Avaliação da aprendizagem escolar. São Paulo: Cortez, 1995.

PERRENOUD, P. Avaliação: da excelência à regulação das aprendizagens: entre duas lógicas. Porto Alegre: Artes Médicas, 1999.

RAMÍREZ, T. G. R. Evaluación inclusiva y calidad educativa: concreciones conceptuales y metodológicas. Revista Educação, Artes e Inclusão, Florianópolis, v.1, n.3, p.19-29, 2010. Disponível em:

<https://docs.google.com/viewerng/viewer?url=http://www.revistas.udesc.br/index.php/artein clusao/article/viewFile/2146/1676>. Acesso em: 14 nov. 2017.

SAMPAIO, C. T.; SAMPAIO, S. M. R. Educação inclusiva: o professor mediando para a vida. Salvador: EDUFBA. 2009.

SANTIUSTE, V. B.; ARRANZ, M. L. Nuevas perspectivas em el concepto de evaluación. Revista de Educación, Madri, n.350, p.463-476, sep.-dic. 2009. Disponível em: <http://www.revistaeducacion.educacion.es/re350/re350_20.pdf>. Acesso em: 17 nov. 2017.

UNESCO. Declaração de Salamanca e linha de Ação sobre Necessidades Educativas Especiais. 1994. Disponível em:

<http://portal.mec.gov.br/seesp/arquivos/pdf/salamanca.pdf>. Acesso em: 02 abr. 2016

VALENTIM. F. O. D. Inclusão de alunos com deficiência intelectual: considerações sobre avaliação da aprendizagem escolar. 2011. 143f. Dissertação (Mestrado em Educação) - 
Faculdade de Filosofia e Ciências, Universidade Estadual Paulista, Marília, 2011. Disponível em:

$<$ https://repositorio.unesp.br/bitstream/handle/11449/91198/valentim_fod_me_mar.pdf?seque nce $=1 \&$ isAllowed=y $>$. Acesso em: 14 nov. 2017.

WEISZ, T.; SANCHESZ A. O diálogo entre o ensino e aprendizagem. 2.ed. São Paulo: Ática, 2006.

\section{Como referenciar este artigo}

VITORINO, Stephânia Cottorello.; GREGO, Sonia Maria Duarte. Avaliação enquanto instrumento para nortear a inclusão escolar. Doxa: Rev. Bras. Psicol. Educ., Araraquara, v.19, n.2, p. 200-211, jul./dez. 2017. e-ISSN: 2594-8385.

Submetido em: 01/04/2017

Aprovado em: 30/06/2017 